\title{
Учёнг'е записки
}

Комсомольского-на-Амуре гоцударственного технического университета

Кабанова О. Р., Кузнецова О. Р.

O. R. Kabanova, O. R. Kuznetsova

\section{РОЛЬ ФИНАНСОВОГО МЕНЕДЖМЕНТА В СТРАТЕГИЧЕСКОМ УПРАВЛЕНИЯ КОММЕРЧЕСКОГО БАНКА}

\section{THE ROLE OF FINANCIAL MANAGEMENT IN THE STRATEGIC MANAGEMENT OF THE COMMERCIAL BANK}

Кабанова Ольга Раисовна - магистр кафедры «Экономика, финансы и бухгалтерский учет» Комсомольского-на-Амуре государственного университета (Россия, Комсомольск-на-Амуре); 681013, Хабаровский край, г. Комсомольск-на-Амуре, пр. Ленина, 27. E-mail: www.olga-sh0902@mail.ru.

Ms. Olga Kabanova - Master's Degree Student, Economy, Finance and Accounting Department, Komsomolskon-Amur State University (Russia, Komsomolsk-on-Amur); 27, Lenin ave., Khabarovsk region, Komsomolsk-onAmur, 681013, Russia. E-mail: www.olga-sh0902@mail.ru.

Кузнецова Ольга Рудольфовна - доцент кафедры «Экономика, финансы и бухгалтерский учет», кандидат экономических наук Комсомольского-на-Амуре государственного университета (Россия, Комсомольск-наАмуре); 681013, Хабаровский край, г. Комсомольск-на-Амуре, пр. Ленина, 27. E-mail: orkuznetsova@mail.ru.

Ms. Olga R. Kuznetsova - Associate Professor, $\mathrm{PhD}$ in Economic Sciences, Economy and Finance Department, Komsomolsk-on-Amur State University (Russia, Komsomolsk-on-Amur); 27, Lenin ave., Khabarovsk region, Komsomolsk-on-Amur, 681013, Russia. E-mail: orkuznetsova@mail.ru.

Аннотация. Финансовый менеджмент является одним из составных элементов банковского менеджмента. В рамках данного исследования были использованы такие методы научного исследования, как изучение и анализ нормативно-правовой базы, изучение монографических публикаций и статей, аналитический метод. Авторы предлагают классифицировать финансовый банковский менеджмент на тактический и стратегический в зависимости от временного фактора целей. При определении роли финансового менеджмента в стратегическом управлении коммерческим банком необходимо снова обратить внимание на первостепенную роль финансовой стратегии, которая определяет перспективное развитие и направление практической реализации финансовой банковской деятельности.

Summary. Financial management is one of the constituent elements of banking management. Within the framework of this research, such methods of scientific research as the study and analysis of the regulatory framework, the study of monographic publications and articles, and the analytical method were used. The authors propose to classify financial banking management as tactical and strategic, depending on the time factor of the goals. Defining the role of financial management in the strategic management of a commercial bank, it is necessary to pay attention to the paramount role of a financial strategy that determines the perspective development and direction of the practical implementation of financial banking activities.

Ключевые слова: банковский финансовый менеджмент, стратегическое управление, тактическое управление, иерархия принципов, управление финансами коммерческого банка.

Key words: bank financial management, strategic management, tactical management, the hierarchy of principles, management of finance of a commercial bank.

\section{УДК 338.2}

Эффективная деятельность современных коммерческих банков, обеспечение высоких темпов их развития, отвечающих потребностям экономики и населения страны, повышение конкурентоспособности и финансовой устойчивости в значительной степени определяются качеством банковского управления финансовыми ресурсами. Привлечение финансовых ресурсов является жизненно важной задачей, без решения которой коммерческие банки не могут существовать. Способ- 
ность банка привлекать депозиты и межбанковские кредиты, осуществлять размещение собственных ценных бумаг является основным критерием признания банка со стороны различных субъектов финансового рынка. А состояние ресурсной базы коммерческого банка является главным критерием оценки стабильности и надежности банка, индикатором качества обслуживания банком клиентов. Управление формированием ресурсной базы коммерческих банков призвано обеспечить оптимальный объем привлеченных ресурсов на длительные сроки с наименьшими затратами.

В процессе реализации стратегического управления коммерческому банку необходимо задействовать все структурные элементы управленческого процесса, посредством чего используются такие виды организации управления, как финансовый менеджмент, организационное управление, управление персоналом организации, маркетинговый подход. Однако основную роль в достижении конкурентных преимуществ будет составлять финансовый менеджмент, в связи с чем данный элемент стратегического управления требует наиболее детального изучения.

Финансовому менеджменту присущи такие признаки, как структура, элементы, компоненты, комплекс подцелей, внутренние и внешние возмущающие воздействия, общая цель управления, а также информационные ресурсы.

Структура системы финансового менеджмента представлена на рис. 1. В ней выделена прежде всего управляющая система, воздействующая на объекты финансового менеджмента через призму финансовой стратегии.

Компоненты системы финансового менеджмента подразделяются на базовые и вторичные. К базовым компонентам можно отнести: управляющую систему, управляющую подсистему и объекты управления. Вторичные компоненты могут быть представлены следующими элементами: финансы, финансовые ресурсы, денежные фонды, источники финансирования.

В процессе функционирования системы финансового менеджмента управляющая система в лице органов власти, собственников или управляющих организаций формирует цели, подцели и задачи управления.

Процесс воздействия может происходить как непосредственно, так и через управляющую подсистему. Как результат воздействия к управляющей системе поступает обратный информационный поток, который может быть предварительно проанализирован управляющей подсистемой.

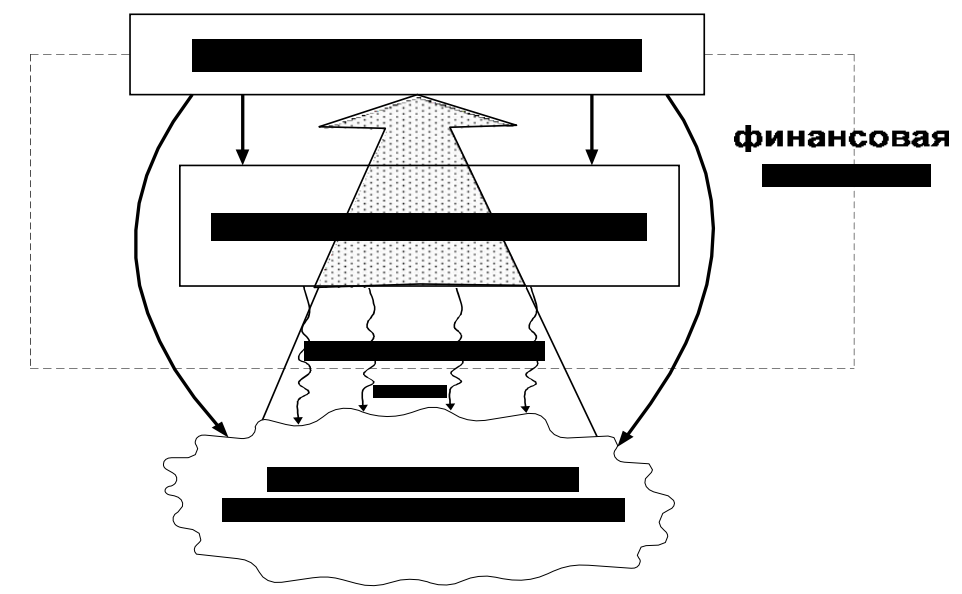

Рис. 1. Структура системы финансового менеджмента

На денежном рынке в условиях конкурентной борьбы коммерческие банки вырабатывают собственные регламенты осуществления финансового управления. Для отечественных банков характерна регулярная корректировка сложившихся приемов ведения управленческих процессов, однако все приемы и методы управления обязаны отвечать единой концепции развития банковского сектора, определенной ЦБ Российской Федерации.

Финансовый менеджмент является важнейшим компонентом стратегического управления коммерческим банком в связи с тем, что охватывает наиболее значительную совокупность управ- 


\section{Учёные записки}

Комсомольского-на-Амуре государственного технического университета

ляемых структурных объектов. В него входит и такой элемент, как управление персоналом. Следующим аргументом, позволяющим говорить о важности финансового менеджмента в банковском управлении, являются нехватка денежных средств и краткосрочность финансовых ресурсов в Российской банковской системе [3, 185]. Данную проблему можно решить лишь с помощью разработки грамотной концепции банковского финансового менеджмента. Особенно значимыми результаты в данной области управления становятся в кризисные периоды в банковской системе.

В период финансового кризиса наиболее актуальным становится вопрос о создании финансово устойчивой модели функционирования коммерческого банка. Разработка основной концепции банковского финансового менеджмента способствует социально-экономическому развитию национальной экономики и росту благосостояния населения страны.

Теоретические основы банковского финансового менеджмента базируются на общих положениях финансового менеджмента хозяйствующих субъектов, отражая тесную взаимосвязь механизмов управления финансами хозяйствующих субъектов с механизмами функционирования и инструментами финансового рынка.

Однако финансовый менеджмент в банке необходимо рассматривать с учетом особенностей банковской деятельности, связанной как со структурой формирования ресурсной базы, так и с созданием специфического продукта - платежных средств - и организацией системы управления всеми функциями денег. Он представляет собой гибкий механизм управления, который ориентирован на быстрые изменения во внешней и внутренней среде хозяйствования $[8,16]$.

Еще одной отличительной чертой финансового менеджмента коммерческого банка являются его структурные элементы: финансовая политика; активы и пассивы; собственный капитал; кредитный портфель; риск-менеджмент; банковский маркетинг; ликвидность; прибыль (доходность).

Необходимо отметить, что существует взаимосвязь между данными объектами.

П. А. Продолятченко, делая анализ специфики банковского финансового менеджмента, выделяет превалирующую парадигму современного финансового управления в банковской сфере [6, 79]. Согласно данной концепции, это «депозитно-кредитная» парадигма банковского финансового менеджмента. Методологической базой данной концепции служит теория финансового посредничества Д. Полфренмана и Ф. Форда $[9,100]$. Данная парадигма, по мнению П. А. Продолятченко, в настоящее время сменяется парадигмой «инвестиционного» финансового менеджмента, которая превращает предыдущую в подчиненную. При этом применяются финансовые механизмы формирования банковских ресурсов, ориентированные на долгосрочные, стратегические цели банковского бизнеса.

На современном этапе развития банковской системы кредитные учреждения значительно расширили свою функциональную деятельность, не ограничиваясь кредитно-депозитными операциями, что в свою очередь приводит к расширению их деятельности в области банковского финансового менеджмента. На сегодняшний день происходит трансформация всей системы банковского управления, которая не может не коснуться и финансовой составляющей. По этой причине мы считаем, что модель, которую предлагает А. П. Продолятченко, подошла бы применительно к отечественной банковской системе десятилетней давности.

Таким образом, можно сделать вывод, что банковский финансовый менеджмент нельзя характеризовать только как систему управления финансовыми потоками коммерческого банка.

Стратегический финансовый менеджмент связан с реализацией стратегии и миссии банка, a также с решением перспективных задач посредством критериального управления. Тактический финансовый менеджмент гарантирует решение текущих задач посредством постоянного управления согласно отклонениям, реализующих принцип обратной связи.

Классификация принципов банковского финансового менеджмента уже была разработана рядом отечественных авторов [4, 245-246; 1, 17-18; 10, 214]. При этом зачастую происходит процесс агрегирования принципов банковского управления с принципами банковского финансового менеджмента.

А. П. Продолятченко предлагает систему принципов финансового менеджмента объединить в два основных разноплановых блока принципов: принципы банковского финансового ме- 
неджмента, связанные с привлечением финансовых ресурсов, и принципы банковского финансового менеджмента, связанные с использованием финансовых ресурсов.

Однозначно отнести все принципы к стратегическим или тактическим, кроме «согласованности со стратегией управления коммерческим банком», нельзя. Все они, в какой-то мере, относятся и к тому или другому направлению $[7,430]$.

В настоящее время существенное значение в процессе функционирования финансового менеджмента в коммерческих банках отводится не финансовому или аналитическому учету, а технократическому подходу, ориентированному на информацию и управление потоками данных.

При проведении анализа значимости финансового менеджмента в системе управления коммерческим банком необходимо рассмотреть требования, которым он должен отвечать в процессе своей реализации. На наш взгляд, этими требованиями являются:

1. методологическая разработанность процесса реализации финансового менеджмента применительно к данному коммерческому банку - предполагает предварительную разработку методологий и методик его осуществления на основе анализа специфики коммерческого банка, непосредственно в которой он будет реализован;

2. эффективность и результативность в ходе его реализации - предполагается разработка системы критериальных показателей эффективности реализации финансового менеджмента коммерческого банка;

3. интеграция с общей системой управления - предполагается «единство» посредством целей, задач, принципов, стратегий с общей системой управления банка;

4. унифицированность стандартов и документации - позволяет рационально организовать и агрегировать финансовую документацию по единым требованиям с целью оптимального управления коммерческим банком.

Организационные методы управления представляют собой способы, приёмы, с помощью которых создаются разнообразные социальные системы (организации, предприятия, учреждения), осуществляется воздействие на систему, её части и элементы и обеспечивается определенный уровень (качество) их организованности.

Финансовый менеджмент в рамках стратегического управления коммерческим банком позволяет обеспечить сбалансированность мероприятий его финансовой деятельности по каждому направлению на долгосрочный период времени.

Таким образом, от качества процесса реализации финансового менеджмента в коммерческом банке будут зависеть результаты его финансовой деятельности и его финансовая устойчивость, что в свою очередь отражается на возможности функционирования в долгосрочной перспективе и на осуществлении стратегического управления в целом.

\section{ЛИТЕРАТУРА}

1. Жукова, Е. Ф. Банковский менеджмент: учеб. для студентов вузов / Е. Ф. Жукова. - М.: ЮНИТИ-ДАНА, 2009.

2. Геращенко, В. В. Россия и деньги. Что нас ждет? / В. В. Геращенко. - М.: Астраль: Русь-Олимп, 2009.

3. Керженцев, П. М. Принципы организации. Избранные произведения / П. М. Керженцев. - М.: Экономика, 1968.

4. Основы банковского дела: учеб. пособие / под ред. Г. Г. Коробовой и Ю. И. Коробова. - М.: Магистр, 2016.

5. Поморина, М. А. Концепция финансового управления в системе стратегического менеджмента банка: дис. ... д-ра экон. наук: 08.00.10 / Поморина Марина Александровна. - М., 2009. - 562 с.

6. Продолятченко, П. А. Прадигма финансового менеджмента / П. А. Продолятченко // В мире научных открытий. -2010 . - № 1(07). - Ч. 2. - С. 77-82.

7. Синки, Дж. Ф. Финансовый менеджмент в коммерческом банке и индустрии финансовых услуг / Дж. Ф. Синки. - М.: Альпина Бизнес Букс, 2007.

8. Хольнова, Е. Г. Системно-структурные характеристики банковского финансового менеджмента Е. Г. Хольнова // Проблемы современной экономики. - 2015. - № 3(27). 